arriving at the spot. Some ladies decribe a remarkable sensation accompanying the process : a sort of "all-overishness," or even faintness, so much so that the lady first alluded to on one occasion staggered, and could not proceed at all.

It appears to me to be a very peculiar psychological phenomenon well worthy of investigation, if possible, but too well known to be disputed.

6, Titchfield Terrace, Regenı's Park, N.W.

P.S.-Since writing the above I have heard of a much more remarkable case than the preceding. The operators sat in a circle, silent, but determinately "willing" that a certain lady should do what they had resolved upon. She stood in the centre, and was not blindfolded or touched by any one. In every case she did it correctly. One thing that was agreed upon was for her to take a bottle of wine from one table, carry it to another, and pour out a definite quantity of wine. This she did, not exceeding the amount predetermined. On a second occasion she had to find a key hidden away behind some books. As she approached the place she became very excited and hysterical, but at once extracted the key.

The above cases clearly show that as far as they are concerned "thought-reading" is an incorrect expression, as the person operated upon is a passive automaton, while others, as it were, force their wills upon her. "Will-imparting" would seem to be a better term.-G. H.

\section{Notes of the Cuckoo}

IN a letter appearing in NATURE, vol. xxii. p. 76, I stated that-." All the cuckoos here intone in a minor key except one, which alone does not flatten the 3 rd of the tonic. The key is in all cases precisely $D$ of concert pitch, as proved by a tuning fork, and the first note is $F$ on the fifth line." This year I find that, while the cuckoos here generally intone in D minor, as above, there is one again that intones in $\mathrm{D}$ major, and two others in $\mathrm{C}$ major and $\mathrm{C}$ minor respectively. Some that I casually heard in other places in the neighbourhood intoned in D minor.

Millbrook, Tuam, June I John Birmingham

\section{Notes on the Indian Glow-Fly}

Having failed to find any critical description of these interesting insects, it is possible that the notes $I$ am now able to send you may cause others to enter the field of inquiry. Situated some 2900 feet above the sea, and in Central Southern India amidst hills, valleys, and streams, I have had peculiar opportunities for observing them.

They are not to be seen during the daytime, but so soon as darkness steals upon twilight, so surely do these small natural lanterns become visible, and their numbers rapidly increase, much indeed as the visibility of the stars increases as the evening passes into midnight.

The fire-fly, when examined individually, is by no means a pretty-looking insect, and comparing it to other insects and flies, it is certainly both large and ungainly. An ordinary house fly is five-sixteenths of an inch in total length and weighs 25 grains, but the subject of my notice has a total length of nine-sixteenths of an inch and weighs 66 of a grain; we thus at once learn something as to his size and weight. The glow-fly-or beetle as I should term it-has a black head and antennæ; the thorax and abdomen are of a yellow-red colour. This latter part of the insect's body is divided into six rings, and, counting from the thorax, it is the fourth ring that emits the light. There is a rectangular opening in this ring which is merely covered by a very thin skin; it is in fact a windoze from which the light emerges. The insect has only one pair of wings: these are small, most delicate and thin, and are sheathed. It is worthy of careful notice that these insects fly both rapidly and slowly, but make no noise or buzz in the air. To test this further I have frequently liberated several of these glow-beetles in my bedroom, and in the dark they have only appeared as fairy stars, as no humming could be detected.

As regards the character and quantity of the light, I have to observe that one insect enables me to see the time by a whitefaced watch when four inches distant; twelve of them placed in a glass jar enable me to read a book w ith ease, and are equal to a small Geissler's tube. The light is of an exceedingly beautiful colour-a sombre yellow tinged with green, but at intervals it is brilliant. A preliminary examination of the light in the spectroscope (a large one made for me by Browning) show's a distinct clear continuous spectrum, no lines or bands of any kind being visible.

The insect made to crawl on a card placed over the poles of a powerful compound permanent magnet showed no signs of uneasiness or change of light. Similarly placed over an electromagnet (ten Grove cells) and rapidly alternating the current caused no change. Placed within a coil of covered wire, no change. Blowing very gently, my breath on the insect caused no change ; this was also tried with a blowpipe. Cold air at $50^{\circ}$ caused a distinct diminution of the light; on the other hand, air at $100^{\circ}$ caused an increase of light.

I now placed several of the insects in a bell-jar, and gave them a good supply of clean oxygen gas; the luminosity at once increased fully 25 per cent. On a dead insect (which still sheds light) oxygen gave similar results, and on extracting the luminous part and blowing oxygen upon it the light was much increased.

It will prove interesting to mention that, so soon as darkness bas fairly set in, millions of these insects invade the trees, and as my bungalow is near to a stream and level with the tops of the trees, I am able to notice them with much care. The curious pulsation or flashing of their light is remarkable: the insects resting on the tree all act in perfect concert, i.e. five seconds of no light, then seven rapid flashes; five seconds, no light, seven flaches; and so the game continues throughout the dark hours.

At first I had reason to believe that the insect when flyirg only emitted light; this however is not the case; for when observing the Pole Star for variation with my theodolite, it occurred to me during a passing clond to turn a telescope on to the glowing tree. At once I had the field of view filled with tiny stars, but both fixed and wandering.

It is also worthy of special notice that all the glow-insects on a dozen or more trees will continue to keep up the most perfect time as to the flashing of their light and the interval of pause, and this for many consecutive hours; but this singular agreement as to the time relates to close clusters of trees only. Thus distinct groups of trees separated by one or more hundred yards may not agree, and do not do so as a rule.

I have been informed on safe authority that the Indian bottle. bird protects his nest at night by sticking several of these glowbeetles around the entrance by means of clay; and only a few days back an intimate friend of my own was watching three rats on a roof rafter of his bungalow when a glow-fly lodged very close to them; the rats immediately scampered off.

In conclu ion, these insects see by day as well as by night, and I incline to the idea that the beautiful light they carry serves as a means of intimidation or protection, and certainly as a means whereby to recognise friends.

As I gaze from my verandah down the Nadgani Valley into the dark night I see the pulsations of light here, there, and everywhere! and as my optical powers increase so do these gaseous, nebulous patches become resolved into real living stars!

Wynaad, India, May 5

\section{Birds Suffering from Cold}

THE unusually severe weather $\left(5^{\circ}-12^{\circ}\right.$ Réaumur) of [these last twelve days struck heavily on the swallows of our country. They have been found dead by hundreds. The distress of the poor animals must have been extreme. Suffering from hunger and cold, they pressed against the windows, and being brought in suffered to be petted and fed, but died from exhaustion. In Kopidno about 300 took shelter under a balcony, and the cold growing more and more intense towards night, they clustered on each other like bees until morning, when thirty were found dead. I have been walking this afternoon in the suburbs of Prague, where a fortnight ago I have seen swallows skipping on the river and hunting in gardens, but although the weather was now clear and warm, I could not see a single one. Tidings of suffering swallows come from the country, where people have been kind to them, feeding them on ants' eggs and flies, but they would not eat, and died. In some nests the young ones were found starved alone, in others their mothers were with them.

Prague, June 16 J. V. SLÁDEK

\section{An Optical Illusion}

THE illusion of the inverted pin was shown me about the year I $846-47$, and I well remember, when I was at Cambridge, 